\title{
A dimensão política do orçamento público: os conselhos de direitos como espaço de debate plural e coletivo
}

\section{A political dimension of public budget: the councils of rights as a space for collective and plural debate}

\author{
Valdir Anhucci ${ }^{1}$ \\ Vera Lucia Tieko Suguihiro ${ }^{2}$
}

\section{Resumo}

A consolidação da dimensão política dos Conselhos de Direitos está vinculada à sua compreensão como espaços públicos plurais, da divergência e de constante disputa de ideias. A sua dimensão política torna-se determinante, em especial, no processo de definição e gestão do orçamento público tanto para o planejamento quanto para ampliação do debate sobre o destino de recursos financeiros para a implementação de políticas públicas. É nesse espaço que os diferentes interesses se manifestam, tornando-se um campo de disputa política para apropriação dos recursos públicos na garantia dos direitos e proteção social dos segmentos mais vulnerabilizados da sociedade. O orçamento público nos espaços dos conselhos ganha uma dimensão política, superarando a perspectiva de mero instrumento contábil.

Palavras-chave: Dimensão Política. Espaço Público. Conselhos de Direitos. Orçamento Público.

\begin{abstract}
The consolidation of the political dimension of the Councils of Rights is linked to its understanding as plural public spaces, divergence and the constant struggle of ideas. The political dimension becomes crucial, especially in the process of defining and managing the public budget for both planning and to expand the debate on the allocation of financial resources for the implementation of public policies. It is this space that the different interests manifest themselves, becoming a field of political struggle for the appropriation of public resources in ensuring the rights and social protection of the most disenfranchised segments of society. The public budget in the spaces of advice gained a political dimension, the prospect of mere instrument accounting.
\end{abstract}

Keywords: Political Dimension. Public Space. Councils of rights. Public budget.

\footnotetext{
${ }^{1}$ Universidade Estadual do Paraná - Campus Apucarana. Mestre em Serviço Social e Política Social pela Universidade Estadual de Londrina. E-mail: anhucci@yahoo.com.br.

${ }^{2}$ Doutora em Serviço Social -PUC/SP. Departamento de Serviço Social. Universidade Estadual de Londrina. e-mail: suguihiro@uel.br.
} 


\section{INTRODUÇÃO}

Diante da sistemática orçamentária prevista na Constituição Federal de 1988, o Brasil passa a ter um novo instrumento de planejamento a ser elaborado pelas três esferas de governos. Trata-se do Plano Plurianual (PPA), da Lei de Diretrizes Orçamentária (LDO) e da Lei Orçamentária Anual (LOA), que se constituem nos elementos centrais para a composição das leis reguladoras da atividade orçamentária. A destinação e a aplicação de recursos para o financiamento das políticas sociais exigem o acompanhamento e o controle dos diferentes atores sociais, haja vista que se trata de dinheiro público.

Sendo assim, a inserção de novos atores sociais no debate sobre o orçamento público não é algo secundário, mas essencial, tendo por condição o exercício da participação e do controle social, capazes de garantir maior visibilidade às decisões tomadas no que diz respeito ao emprego dos recursos públicos.

$\mathrm{Na}$ Constituição Federal de 1988, o processo de planejamento orçamentário ganha uma dimensão política dentro dos espaços públicos deliberativos, na medida em que assuntos de interesse público sejam submetidos ao debate plural, levando em consideração a expressão e o acesso de temas que influenciam diretamente na vida cotidiana dos diversos atores sociais.

Atualmente organizações e movimentos sociais tem se mobilizado para exigir maior transparência e controle social no orçamento público. O compromisso é de lutar pela democratização do debate e das decisões sobre os recursos públicos, exigindo uma maior transparência nas ações do Estado e o acesso público às informações.

Nesta perspectiva, tanto a dimensão política dos espaços públicos deliberativos quanto do orçamento público passam por uma redefinição da relação entre Estado e sociedade civil, o que significa a democratização da tomada de decisões sobre o orçamento público. Assim, o Estado deve se responsabilizar pelo provimento de políticas públicas, o que exige o reconhecimento de sua atribuição na destinação de recursos no orçamento público. Cabe à sociedade civil, por sua vez, cumprir o seu papel de defesa em favor de maiores investimentos nas políticas sociais e exercer o controle dos gastos públicos. 
Entretanto, a sociedade brasileira, historicamente, vem se caracterizando pela ausência de um debate crítico no que diz respeito às tomadas de decisões em torno das políticas sociais, em especial, no que se refere às definições sobre os rumos do orçamento público. A gestão pública foi, e ainda é, marcada por posturas autoritárias e clientelistas dificultando o acesso dos sujeitos sociais às decisões de caráter político, agravada pela prevalência de um Estado sob o domínio do projeto neoliberal.

Nesta perspectiva, os Conselhos de Direitos, enquanto lócus capaz de democratizar o debate sobre o orçamento público ficam desqualificados. O que tem prevalecido é um Estado que prioriza políticas públicas para atender o interesse do mercado, sem permitir que a sociedade civil possa expressar suas reinvindicações.

Assim, o presente trabalho busca discutir a importância da dimensão política do processo de definição e gestão do orçamento público, tendo como campo de mediação o espaço dos Conselhos de Direitos.

\section{A DIMENSÃO POLÍTICA DO ORÇAMENTO PÚBLICO ENQUANTO PROCESSO DE CONSTRUÇÃO E CONSOLIDAÇÃO DAS POLÍTICAS SOCIAIS}

A postura autoritária e conservadora do Estado brasileiro tem dificultado a aproximação da população dos espaços de decisões políticas no âmbito da gestão pública. Trata-se de uma tradição histórica contrária à radicalização da democracia. Segundo Nogueira (1998), o próprio Estado deixou de contribuir para a autoorganização da sociedade, priorizando uma cultura política autoritária e golpista. Esta cultura pressupunha um espaço público regulado pelo Estado, mesmo que ocupado pela sociedade civil, de forma a levar o país a conviver com "baixas taxas de predisposição democráticas e instituições representativas pouco operantes" (NOGUEIRA, 1998, p. 222). Assim, diante de um processo de despolitização, os cidadãos se tornam passivos, delegando ao Estado a condução das mudanças, sem exercer o controle sobre a coisa pública.

Para Chauí (1994), a sociedade brasileira é verticalizada e hierarquizada. Embora isso seja ocultado, as relações sociais se dão a partir da ordem de um superior e da obediência de um inferior. Holanda (1995, p.39) afirma que no Brasil “[...] um único princípio político verdadeiramente forte foi a obediência [...]”. Chauí (2006, p 353) reforça que: 
Conservando marcas da sociedade colonial escravista, a sociedade brasileira caracteriza-se pelo predomínio do espaço privado sobre o público e, tendo o centro na hierarquia familiar, é fortemente hierarquizada em todos os seus aspectos: nela, as relações sociais e intersubjetivas são sempre realizadas como relação entre um superior, que manda, e um inferior, que obedece. As diferenças e assimetrias são sempre transformadas em desigualdades que reforçam a relação mandoobediência. O outro jamais é reconhecido como sujeito nem como sujeito de direitos, jamais é reconhecido como subjetividade nem como alteridade.

Sendo assim, o fato da população não se apropriar dos espaços públicos é, em parte, fruto de uma estrutura social e política que historicamente limitou o acesso da população às decisões políticas.

No entanto, a partir da década de 1980, Telles (1999) chama a atenção para o movimento contrário à estrutura desigual e injusta que se apresentava no Brasil. Os enfrentamentos encabeçados por sindicados, movimentos sociais e outros setores da sociedade civil organizada, [...] deixaram suas marcas em conquistas importantes na Constituição de 1988 e se traduziram na construção de espaços plurais de representação de atores coletivos reconhecidos como interlocutores válidos no cenário nacional (TELLES, 1999 p. 17). No horizonte deste processo de interlocução,

[...] está a possibilidade da construção de novas formas de regulação das relações sociais através dos 'rituais da negociação', ancorados no terreno dos conflitos, abertos à pluralidade de problemas e temas emergentes que não encontram lugar no espaço unitário estatal, às contingências sempre imprevistas do conflito social e que deslocam o poder do Estado como árbitro exclusivo, bem como ampliam as fronteiras das relações de direito para além do que é definido como código jurídico e regra formal da lei [...]. A questão diz respeito à possibilidade da construção, entre, Estado, economia e sociedade, de arenas públicas que deem visibilidade aos conflitos e ressonância às demandas sociais, permitindo, no cruzamento das razões e dos valores que conferem validade aos interesses envolvidos, a construção de parâmetros públicos que reinventem a política no reconhecimento dos direitos como medida de negociação e deliberação de políticas que afetam a vida de todos (TELLES, 1994, p.12).

É a partir da negociação, da administração dos conflitos de interesses, das deliberações políticas e da ocupação dos espaços públicos é que se abre um campo de possibilidades para superação de posturas autoritárias e para viabilizar uma gestão pública mais democrática.

Neste contexto político, o debate sobre o orçamento público ganha maior visibilidade. Esta é respaldada pela nova proposta de gestão pública instituída pela 
Constituição Federal de 1988. O avanço está na possibilidade do debate ser ampliado, envolvendo diferentes atores sociais no processo decisório dos recursos públicos e alterando o modelo de gestão pública que historicamente prevaleceu no Brasil.

Cumpre destacar que a atual constituição exige a compreensão do significado do que é "público", a fim de que se possa atribuir o valor necessário ao espaço público enquanto lócus de debate e de decisão de caráter político. Arendt (2010), ao se referir ao termo "público" chama a atenção para dois fenômenos que tem uma correlação, mas que não são considerados idênticos. O primeiro significa,

[...] que tudo o que aparece em público pode ser visto e ouvido por todos e tem a maior divulgação possível. Para nós, a aparência - aquilo que é visto e ouvido pelos outros e por nós mesmos - constitui a realidade. Em comparação com a realidade que decorre do ser visto e ouvido, mesmo as maiores forças da vida íntima - as paixões do coração, os pensamentos do espírito, os deleites dos sentidos - levam uma espécie de existência incerta e obscura, a não ser que, e até que, sejam transformadas, disprivatizadas e desindividualizadas, por assim dizer, de modo que assumam um aspecto adequado à aparição pública. [...] a presença de outros que veem o que vemos e ouvem o que ouvimos garante-nos a realidade do mundo e de nós mesmos [...]. Uma vez que nosso senso da realidade depende totalmente da aparência e, portanto da existência de um domínio público no qual as coisas possam emergir da treva de uma existência resguardada, até a meialuz que ilumina nossas vidas privada e íntima deriva, em última análise, da luz muito mais intensa do domínio público (ARENDT, 2010 p. 61 e p. 63).

Assim, tudo o que é tornado público, ou seja, que pode ser apreciado por todos, tem haver com a realidade de cada um. Ao excluir parcela significativa da população do debate em torno de questões de interesse comum, inviabilizam-se ações que possam atender ao interesse coletivo, e as decisões tomadas de forma individual ou corporativa não favorecerão a realidade de todos. Neste sentido, é preciso ter claro o que é de interesse comum e aquilo que não é. Não se trata de desconsiderar a importância que cada um dá para questões de caráter privado. Mas, é fundamental levar a público aquilo que de fato é de interesse coletivo. Nesta perspectiva, Arendt (2010, p. 63) reforça que,

[...] há muitas coisas que não podem suportar a luz implacável e radiante da constante presença de outros na cena pública. Nesta, só pode ser tolerado o que é considerado relevante, digno de ser visto e ouvido por todos, de forma que o irrelevante se torna automaticamente um assunto privado. 
Isto remete ao entendimento de que tudo o que é público não pode, em hipótese alguma, ser entendido como algo restrito a uma parcela da sociedade. $\mathrm{O}$ que é público deve ser submetido ao olhar de todos. Não é tolerável que os assuntos de interesse comum estejam sujeitos à apreciação e condução de uma minoria. Aquilo que é relevante para o conjunto da sociedade requer o envolvimento máximo de pessoas, a fim de construir prioridades que atendam aos interesses coletivos. É nesta perspectiva que o debate sobre o orçamento público ganha a dimensão política no âmbito dos conselhos, na medida em que é capaz de expressar de forma clara e explícita as reinvindicações da sociedade.

Ainda para Arendt (2010, p. 64), o termo “público” é o próprio mundo, uma vez que o mesmo "[...] é comum a todos nós e diferente do lugar que privadamente possuímos nele. Esse mundo, contudo, não é idêntico a Terra ou a natureza, enquanto espaço limitado para o movimento dos homens e a condição geral da vida orgânica". Trata-se, portanto, de um mundo em que ao mesmo tempo separa, mas também exige momentos em que os homens se relacionem entre si, ou seja,

\begin{abstract}
A importância de ser visto e ouvido por outros provém do fato de que todos veem e ouvem de ângulos diferentes. É esse o significado da vida pública, em comparação com a qual até a mais fecunda e satisfatória vida familiar pode oferecer somente o prolongamento ou multiplicação de cada indivíduo, com seus respectivos aspectos e perspectivas. A subjetividade da privatividade pode prolongar-se e multiplicar-se na família e até tornar-se tão forte que o seu peso se faça sentir no domínio público; mas esse 'mundo' familiar jamais pode substituir a realidade resultante da soma total de aspectos apresentados por um objeto a uma multidão de expectadores. Somente quando as coisas podem ser vistas por muitas pessoas, em uma variedade de aspectos, sem mudar de identidade, de sorte que os que estão à sua volta sabem que veem identidade na mais completa diversidade, pode a realidade do mundo aparecer real e fidedignamente (ARENDT, 2010, p. 70).
\end{abstract}

Portanto, o entendimento do termo "público" apresentado pela autora demonstra que tudo aquilo que for de interesse comum deve ser submetido ao julgamento de todos. Nesta perspectiva, Arendt (2010, p. 71) coloca que a existência do mundo comum é resultado de múltiplos olhares, de forma que o mesmo "[...] acaba quando é visto somente sob um aspecto e só se lhe permite apresentar-se em uma única perspectiva".

Assim, a discussão ora apresentada remete para a reflexão e ao entendimento sobre espaço público e a expressão de sua dimensão política. Isso implica na valorização do dissenso, da pluralidade e de uma proposta que vai ao 
encontro da radicalização da democracia. Trata-se da construção do espaço público capaz de pautar questões que vão além dos interesses privados, deste ou daquele grupo, em que a diferença de pensamento seja encarada como uma virtude e não como um problema, seja a regra e não a exceção.

Nesta perspectiva, os Conselhos de Direitos ao serem revestidos destas características contemplam a dimensão política, cuja direção é capaz de alterar a gestão pública, de modo a provocar mudanças substantivas no processo decisório.

No que se refere às decisões do orçamento público, o mesmo não pode ser objeto de debate restrito, mas deve ser submetido ao olhar de todos os interessados, garantindo a sua dimensão política, na medida em que o projeto de interesse coletivo ganha maior visibilidade.

Neste sentido, Semeraro (1999, p. 82) afirma que "[...] o lugar decisivo onde se gestam os diversos projetos hegemônicos é o amplo e contraditório espaço da sociedade civil", onde "[...] se estabelecem 'lutas de sistemas, lutas entre modos de ver a realidade'”. Trata-se, portanto, do lugar onde a política deve estar sempre presente. Para Mouffe apud Burgos (2007) é necessário um modelo de democracia que tenha condições de apreender o verdadeiro sentido do político que, na visão do autor, exige dar centralidade a questão do poder e do antagonismo. Desta forma,

[...] o ideal de uma democracia pluralista não pode se alcançar um consenso racional na esfera pública. Esse consenso não pode existir. Devemos aceitar que cada consenso existe como resultado temporário de uma hegemonia provisória, como estabilização do poder e que ele sempre acarreta alguma forma de exclusão. Ideias de que o poder poderia ser dissolvido por meio de um debate racional e de que a legitimidade poderia ser baseada na racionalidade pura são ilusões que podem colocar em risco as instituições democráticas (MOUFFE apud BURGOS, 2007, p. 132).

Sendo assim, o espaço público pode ser considerado um espaço eminentemente político. É a própria valorização da política. Neste sentido, a discussão sobre o orçamento público no espaço dos Conselhos de Direitos deve ser pautada pela disputa e enfrentamento entre os diferentes interesses, a fim de que não prevaleça a visão unitária da classe dominante. Daí, para Arendt (2002), a política significa pluralidade de homens, em que se obriga a convivência entre o diverso e diz respeito à organização dos homens com vistas a alcançar algo em comum. Desta forma, a autora chama a atenção para o fato de que a política não é algo em que o homem nasce com ela, mas é externo ao mesmo, na medida em que 
a política se dá no momento das relações entre os homens. Nesta perspectiva, pensar na dimensão política do orçamento público, mediada pelos Conselhos de Direitos, implica em dar visibilidade a luta política nestes espaços, considerando-os lócus para construção do processo democrático, onde se estabelece o confronto de interesses, privilegiando a diversidade de ideias e o debate plural.

Paoli (2007) afirma que uma gestão pública inovadora exige da população a capacidade de julgar. No entanto, na maioria das vezes, os programas sociais são legitimados de forma obscura, sem, contudo, levar em consideração a avaliação e o julgamento político da população beneficiária da ação.

Assim, a inovação no âmbito da gestão pública, só se dá pela via da política, valorizando

[...] uma esfera pública na qual os atores, diferentes e desiguais, pudessem se manter dentro do debate plural e conflitivo (no sentido arendtiano) de modo a permitir que sua opinião fosse formada a partir de sua experiência confrontada com o exame publicamente debatido do programa, e não algo pronto, trazido pelo programa e conduzido ao debate público (PAOLI, 2007, p.249).

A partir desta linha de raciocínio, quando se trata de orçamento público a posição política dos Conselhos de Direitos é determinante para as tomadas de decisões sobre o direcionamento dos recursos públicos. É a submissão do assunto ao debate público que irá garantir a dimensão política, cuja força é capaz de romper com o autoritarismo ainda prevalente na relação entre os interesses contraditórios do Estado e da sociedade civil. Portanto, a política é

[...] consubstancial à democracia, cujo princípio organizativo está unido à liberdade de expressão, contendo temas políticos e outros, espaço aberto no qual se exprimem todos aqueles que se autorizam a falar publicamente, logo, a assegurar certa publicidade e mediação do seu discurso (WANDERLEY, 1996, p. 96).

Ao fazer referência a Rancière, Oliveira (2007) afirma que a política é constituída pelo dissenso, uma vez que está ligada à divergência de interesses entre os que possuem algo e aqueles que não possuem e, portanto, lutam para ter acesso a algo que ainda não conquistaram. Neste sentido, para o autor a política está vinculada aos conflitos em torno de uma agenda de questões, o que impõe um movimento entre os diferentes atores sociais. Cumpre destacar que a imposição de uma agenda nem sempre significa o êxito em uma determinada disputa. No entanto, 
[...] significa criar um campo específico dentro do qual o adversário, em seus movimentos, tenta, por sua vez, desvencilhar-se da pauta e sair fora da agenda que lhe é oferecida/imposta. É neste intercâmbio, desigual, que se estrutura o próprio conflito, ou o jogo da política. Essa concepção abre as portas para sua permanente reinvenção, no sentido de que toda proposta, e sua resposta, que consiga sair do campo anteriormente demarcado cria um novo campo, que é, em si mesmo, uma nova qualidade dos atores políticos. Há, pois, na política, uma permanente mudança de qualidade (OLIVEIRA, 2007, p. 15).

Sendo assim, no âmbito da sociedade civil, é preciso considerar a diversidade de atores sociais que se encontra em constante contradição, contribuindo para fortalecimento da política com vistas a construir outra hegemonia. Nesta linha de raciocínio, Dagnino; Olvera; Panfichi (2006) afirmam que:

\begin{abstract}
A ação política não se limita à sociedade política, como a teoria da sociedade civil sustenta, mas é parte da lógica da sociedade civil, cujos atores, ao defender projetos na esfera pública e desenvolver a ação coletiva, estão fazendo política, disputando espaços de poder e orientando a política pública. Grasmsci [...] mostra que a sociedade civil é terreno do poder e, portanto, campo da ação política (apud BURGOS, 2007, p. 131).
\end{abstract}

A afirmação acima denota a importância das relações sociais no âmbito da sociedade civil e do Estado, pois a política só se efetiva a partir do confronto de ideias. No que diz respeito às decisões tomadas sobre recursos financeiros que são destinados às políticas sociais públicas, a relevância da dimensão política dos Conselhos de Direitos torna-se ainda maior. Isso significa que os critérios utilizados para o planejamento dos recursos públicos governamentais devem obedecer a parâmetros públicos construídos a partir do debate plural e democrático.

Em uma sociedade sob a égide do projeto neoliberal, frequentemente o debate político é desqualificado e desvalorizado, o que contribui para a individualização da luta. Politicamente ou socialmente, o neoliberalismo "[...] é o projeto de encolhimento do espaço público e da ampliação do espaço privado - daí seu caráter essencialmente antidemocrático -, caindo com uma luva na sociedade brasileira (CHAUÍ, 2006, p. 357)". Diante da realidade atual, em que se nega o pluralismo de ideias, torna-se urgente e determinante consolidarmos espaços que apontam para a divergência de posições, efetivando sua dimensão política.

Chauí (2006) demonstra que o contexto neoliberal contribui para a privatização do público, não só quando o Estado se desresponsabiliza do seu papel 
de garantidor de políticas sociais, mas também quando reforça estrutura social centrada no espaço privado dificultando a constituição da esfera pública. Esta concepção é reforçada por Dagnino (2004), ao afirmar que

[...] o projeto neoliberal operaria não apenas com uma concepção de Estado mínimo, mas também com uma concepção minimalista tanto da política como da democracia. Minimalista porque restringe não apenas o espaço, a arena política, mas seus participantes, processos, agenda e campo de ação. Assim, o encolhimento das responsabilidades sociais do Estado encontra sua contrapartida no encolhimento do espaço da política e da democracia. Ambas devem ser limitadas ao mínimo, esse encolhimento é seletivo e suas consequências são o aprofundamento da exclusão exatamente daqueles sujeitos, temas e processos que passam a ameaçar o avanço do projeto neoliberal (DAGNINO, 2004, p. 108-109).

Neste contexto neoliberal, são grandes os desafios para se efetivar o espaço público, e são enormes os obstáculos no que se refere à ampliação da dimensão política dos conselhos enquanto lócus capaz de democratizar o debate sobre o orçamento público, com o objetivo de exercer o controle social no que diz respeito à coisa pública.

São grandes os desafios para que a discussão sobre o orçamento público seja inserida no âmbito dos Conselhos de Direitos, prevalecendo, por parte de setores conservadores, a clara intenção de não permitir o debate plural sobre o assunto. Segundo Paoli (2007), no Brasil, historicamente, se utilizou de técnicas sociais para desqualificar a política do dissenso e, atualmente, a violência faz parte do rol de medidas para evitar a organização política da população. Assim, tanto o controle, como a violência vem sendo utilizados para "[...] produzir a figuração da incompetência política da população, especialmente quando esta se organiza, se movimenta, aparece autonomamente" (PAOLI, 2007 p. 224).

A autora recorda ainda que, as técnicas sociais de administração e controle adotadas a partir de 1990, se sustentam principalmente pela degradação dos espaços públicos, em favor de regras que favorecem o mercado e por um sistema de decisões políticas e econômicas que dificultam a capacidade de organização e de posicionamento.

Desse modo, elas se apoiam na validade abstrata das suas próprias fórmulas de competências - não apenas no modo técnico de implantar as políticas sociais, mas também na arrogante presunção de que existe um saber especializado imune ao movimento da política. [...] técnicas de controle e violência operam, portanto, num mundo esvaziado de política 
autêntica e de espaços públicos que poderiam acolhê-la, talvez até mesmo nos atos que criam dispositivos de participação popular voltados para formas democráticas de discussão e deliberação ampliadas, que, não obstante, podem ser eles próprios constituídos previamente por desenhos técnicos que delimitam a espontaneidade do debate e previnem transbordamentos indesejáveis. Em outras palavras, é possível que, no próprio ato em que se desenrola a discussão e a deliberação, cassa-se o ato original da política. (PAOLI, 2007, p. 225).

Como se pode verificar está em curso um processo que promove a desorganização política, levando a decadência e a desvalorização do espaço público e, por consequência, atinge a capacidade de ação da população, limitando sua autonomia e liberdade na construção de uma nova realidade.

Quando se trata da condução do orçamento público a situação se agrava ainda mais, na medida em que a atuação dos Conselhos de Direitos é a expressão da apatia política dos cidadãos no processo de deliberação dos recursos públicos e da defesa das políticas sociais. Trata-se, na concepção de Paoli (2007), de um "vazio da política" que, substituída pela violência e por um processo de gestão das populações, leva a ideia de ausência de um mundo partilhado por aqueles que o habitam. Isto implica em substituir "[...] espaços públicos por estratégias de autolegitimação, ao nos convencer que, diante de nossa urgência, o conhecimento especializado de técnicas e fórmulas de intervenção está aí para resolver os problemas com eficácia e nos proteger do incerto" (PAOLI, 2007, p. 226).

Nesta perspectiva, se por um lado os Conselhos de Direitos têm a possibilidade de exercer um papel determinante no processo de gestão do orçamento público, bem como de influir nos investimentos das políticas sociais, por outro lado ainda, são grandes os desafios para que os mesmos expressem sua dimensão política, na perspectiva de materializar as decisões sobre os recursos públicos.

A partir da pesquisa realizada junto a Conselhos de Direitos em 12 municípios da Região Norte do Paraná, tendo por recorte temporal os anos de 2010 e 2011, o estudo identificou que o debate sobre o orçamento público tem se restringido ao domínio dos poderes Executivo e Legislativo. Ao ser entendido pelos conselheiros como instrumento técnico contábil, as prioridades do orçamento público não são definidas a partir do debate plural. Neste caso, os Conselhos de Direitos delegam a terceiros o poder de decidir sobre as necessidades e interesses coletivos 
dos diversos segmentos que representam, comprometendo a dimensão política no processo de democratização da relação Estado e sociedade.

A pesquisa aponta que o orçamento público não tem sido tema recorrente nas discussões dos Conselhos de Direitos. Muitos conselheiros compartilham da ideia de que as decisões sobre o orçamento público são de responsabilidade do poder constituído, não reconhecendo o espaço dos conselhos como instâncias de participação, formulação, deliberação, monitoramento e, fundamentalmente, do exercício de controle social sobre o Estado, na definição e a alocação de recursos financeiros investidos em políticas sociais.

A falta de conhecimento e a ausência de informações sobre o ciclo orçamentário, as fontes e a alocação dos recursos financeiros, tem sido apresentada como um dos fatores que dificultam o debate político sobre o assunto. Há ainda, grande resistência por parte dos gestores públicos em disponibilizar as informações, principalmente vinculadas aos recursos públicos.

A fragilidade da representação política de muitos conselheiros se expressa em suas dificuldades de participação no processo de gestão das políticas sociais públicas, principalmente quando se trata do orçamento público. A cultura da tutela exercida pelo Estado sobre a sociedade ao longo da história política brasileira, não tem permitido ao conselho vislumbrar o seu papel de fiscalizador e controlador do Estado, ou seja, não se percebe que há uma inversão política radical na condução da coisa pública. Perde-se a oportunidade de articular as forças vivas da sociedade organizada para além da atuação institucionalizada dos conselhos. Isto significa ampliar o campo de luta com as demais políticas sociais afins, valorizando a perspectiva da intersetorialidade.

Os Conselhos de Direitos tem dificuldade em assumir o papel de protagonista na formulação das políticas públicas. Ocupam apenas os espaços criados/concedidos pelo Estado, enfraquecendo a correlação de forças dos diferentes projetos sociais em disputa. O espaço rico do dissenso torna-se um espaço do consenso, prejudicando a manutenção da divergência e da polêmica em torno da coisa pública, pois o "(...) encolhimento da cena política produz algo como um curto-circuito entre a dinâmica societária e o universo público da política". (TELLES, 1999, p. 187). Neste sentido, o modelo neoliberal tem determinado a individualização das lutas, a despolitização do espaço público, a privatização e a financeirização das políticas sociais públicas. 
Frente ao exposto, tornam-se urgentes os investimentos na promoção de mudanças no modo de pensar, sentir e agir sobre o processo de formação e aquisição de conhecimento nas questões envolvendo o orçamento público. Além disso, é necessário investir em ações para a qualificação política dos sujeitos sociais envolvidos e comprometidos com o movimento de redemocratização da relação entre Estado e sociedade. Portanto, a qualificação, instrumentalização e domínio de conhecimento sobre a importância política de influir no processo de definição, alocação e controle do orçamento público são fundamentais para a viabilização de recursos que financiam as políticas sociais.

\section{CONSIDERAÇÕES FINAIS}

Submeter ao debate dos diferentes atores sociais as decisões sobre o orçamento público a ser destinado para as políticas sociais públicas significa o fortalecimento da dimensão política do orçamento público mediado nos espaços dos Conselhos de Direitos. Isso exige uma postura diferenciada tanto do Estado como da sociedade civil. Ao Estado compete respeitar as instâncias de decisão, valorizando-as e contribuindo para a sua operacionalização, tanto no âmbito da gestão como no âmbito político. À sociedade civil, por sua vez, compete redimensionar seus conhecimentos e práticas sobre as novas formas de participação e controle social, assumindo os espaços dos conselhos enquanto espaços de tensão e de interesses contraditórios na disputa por um projeto de sociedade. Cabe ainda, exercer o controle sobre o Estado no cumprimento de suas obrigações, socializando informações e executando as políticas públicas necessárias para melhoria da qualidade de vida da população.

A dimensão política dos Conselhos de Direito se expressa quando os atores sociais envolvidos se enfrentam no debate politico em torno da construção de prioridades das políticas públicas para atendimento dos direitos humanos na sua transversalidade. Isso só é possível na medida em que o orçamento público seja compreendido para além de uma peça técnica e/ou mero instrumento de planejamento. Compete aos Conselhos de Direitos assegurarem, por meio de práticas concretas, a dimensão política do orçamento público.

É fundamental a superação de uma cultura política de subalternização ao poder constituído e o rompimento com práticas equivocadas a serviço de interesses 
particulares de determinados segmentos da sociedade. Portanto, o desafio dos Conselhos de Direitos está na possibilidade de resgatar as diferentes formas de ações coletivas, potencializadas pela dimensão política no processo de organização e socialização de informações e no desenvolvimento de uma gestão democrática voltada para o interesse coletivo.

A expressão da dimensão política no âmbito dos conselhos, com o objetivo de influenciar as decisões sobre o orçamento público, passa pelo protagonismo não só dos conselheiros, mas, sobretudo dos diferentes atores sociais que se comprometem com a democratização da gestão de políticas sociais públicas. Segundo Salvador (2010, p. 607) a disputa por recursos do fundo público também deve ocorrer no âmbito da sociedade, na medida em que "[...] o orçamento público é uma espaço de luta política, onde as diferentes forças da sociedade buscam inserir seus interesses". A partir de um estudo feito pelo INESC em 2006, é importante destacar que "[...] na sua dimensão política, o orçamento pode ser visto como uma arena de disputa ou um espaço de luta (ou cooperação) entre vários interesses que gravitam em torno do sistema político" (apud SALVADOR, 2010, p. 607).

É a partir da participação e do exercício do controle social sobre o Estado que a sociedade tem a possibilidade de acionar sua capacidade na defesa incondicional dos direitos humanos. Segundo Dagnino "[...] é um equívoco atribuir aos espaços de participação da sociedade o papel de agentes fundamentais na transformação do Estado e da sociedade" (SOUZA BRAVO e MENEZES, 2012, p. 263). No entanto, cabe à sociedade civil organizada mobilizar as forças políticas em presença, no sentido de monitorar o Estado no cumprimento das determinações legais vigente no país, a fim de exigir do poder público o compromisso com as políticas de proteção social, por meio de investimentos voltados para a garantia e ampliação das políticas sociais públicas.

O grande desafio que está posto é a afirmação da dimensão política do orçamento público, em especial quando se trata de ocupar o espaço dos Conselhos de Direitos para se debruçar sobre o planejamento das ações governamentais. Isso significa que é fundamental valorizar também a dimensão política dos espaços públicos quando o objetivo é definir diretrizes e prioridades sobre os gastos públicos. 


\section{REFERÊNCIAS}

BRASIL, Presidência da República. Constituição Federal de 1988. Brasília, Senado Federal, 1988.

ARENDT, Hannah. A condição humana. 11 ed. revista. Rio de Janeiro: Forense Universitária, 2010.

O que é política. Fragmentos das obras póstumas compilados por Úrsula Ludz. 3 ed. Rio de Janeiro: Bertrand Brasil. 2002.

BRAVO, Maria Inês Souza; MENEZES, Juliana Souza Bravo de. Participação social e controle social na saúde: a criação dos conselhos de gestão participativa do Rio de Janeiro. In: BRAVO, Maria Inês Souza Bravo; MENEZES, Juliana Souza Bravo de (Orgs). Saúde, serviço social, movimentos sociais e conselhos. São Paulo: Cortez, 2012, p. 273-293.

BURGOS, Raúl. Da democratização política à radicalização da democracia: novas dimensões estratégicas dos movimentos sociais.In: DAGNINO, Evelina; TATAGIBA, Luciana (Orgs). Democracia, sociedade civil e participação. Chapecó: Argos, 2007, p. 127-166.

CHAUÍ, Marilena. Cultura e democracia: o discurso e outras falas. 11 ed. revisada e ampliada. São Paulo: Cortez, 2006.

. Raízes teológicas do populismo no Brasil: teocracia dos dominantes, messianismo dos dominados. In: DAGNINO, Evelina (Org.). Anos 90: política e sociedade no Brasil. São Paulo: Brasiliense, 1994. p.19-30.

DAGNINO, Evelina. Sociedade civil, participação e cidadania: de que estamos falando? Em Daniel Mato (coord.). Políticas de ciudadanía y sociedad civil em tiempos de globalización. Caracas: FACES, Universidad Central de Venezuela, 2004. p. 95-110.

HOLANDA, Sérgio Buarque. Raízes do Brasil. 26.ed. São Paulo: Companhia das Letras, 1995.

NOGUEIRA, Marco Aurélio. As possibilidades da política: ideias para a reforma democrática do estado. São Paulo: Paz e Terra, 1998.

OLIVEIRA, Francisco de. Privatização do público, destituição da fala e anulação da política: o totalitarismo neoliberal. In: Oliveira, Francisco de; PAOLI, Maria Célia (Org.). Os sentidos da democracia. 2. ed. Petrópolis: Vozes, 1999. p.55-81.

Política numa era de indeterminação: opacidade e reencantamento. In: OLIVERIA, Francisco de; RIZEK, Cibele Saliba (Orgs.). A era da indeterminação. São Paulo: Boitempo, 2007. p.15-45. 
PAOLI, Maria Célia. O mundo do indistinto: sobre gestão, violência e política. In: OLIVERIA, Francisco de; RIZEK, Cibele Saliba (Orgs.). A era da indeterminação. São Paulo: Boitempo, 2007. p.221-256.

SALVADOR, Evilásio. Fundo público e políticas sociais na crise do capitalismo. Serviço Social e Sociedade, São Paulo, n. 104, p. 605-631, out./dez. 2010.

SEMERARO, Giovanni. Gramsci e a sociedade civil: cultura e educação para a democracia. Petrópolis - RJ: Vozes, 1999.

TELLES, Vera da Silva. Direitos sociais: afinal do que se trata? Belo Horizonte: Ed. UFMG, 1999.

Sociedade civil e os caminhos (incertos) da cidadania. São Paulo em Perspectiva, São Paulo, v.8, n.2, p.7-14, 1994.

WANDERLEY, Luiz Eduardo W. Rumos da ordem pública no Brasil: a construção do público. São Paulo em Perspectiva, São Paulo, v.10, n.4, p.96-106, 1996. 